\title{
A SBEM no terceiro milênio
}

\author{
Ricardo M. R. Meirelles
}

Professor-Associado de Endocrinologia, Pontifícia Universidade Católica do Rio de Janeiro (PUC-Rio), Diretor do Instituto Estadual de Diabetes e Endocrinologia Luiz Capriglione; Rio de Janeiro, RJ, Brasil

Correspondência para: Ricardo M. R. Meirelles Rua Moncorvo Filho, 90 20211-340 Rio de Janeiro RJ r.meirelles@terra.com.br
$\mathrm{D}$ esde a sua criação, em 1950, a Sociedade Brasileira de Endocrinologia e Metabologia (SBEM) teve como principal foco de atenção as atividades científicas. Estas eram, na realidade, o grande objetivo do grupo de professores que a idealizou, conforme rezava o seu primeiro estatuto. Enquanto as Faculdades de Medicina se dedicam à formação profissional e ao aprimoramento acadêmico, as sociedades médicas são, sem dúvida, as principais responsáveis pela educação continuada, com a realização de congressos, simpósios, jornadas, oficinas e cursos de atualização. Desnecessário enfatizar a importância da atualização, diante do enorme volume de informação que surge a cada momento. Não é fácil manter-se em dia com os avanços da nossa especialidade. O terceiro maior aumento no número de pesquisas clínicas realizadas entre 2005 e 2007 verificou-se no âmbito da Endocrinologia, sendo esta a quinta colocada em volume total de protocolos registrados nesse período (1).

Com a virada do milênio, entretanto, a SBEM enveredou por novos caminhos. Seu perfil mudou. Ou melhor, enriqueceu. Sem descuidar das atividades científicas, a Sociedade passou a se preocupar com a divulgação da imagem do endocrinologista, por meio de campanhas de esclarecimento sobre o seu papel na Medicina. O prefixo endócrino, diferentemente de cardio, gineco, gastro, pneumo, procto e uro, por exemplo, era (e ainda é) pouco conhecido do público leigo. Tanto que todos esses outros constam como "prefixos", no dicionário Aurélio, enquanto endócrino é citado apenas como "adjetivo".

Nessa ocasião, também, reuniram-se recursos que permitiram adquirir uma sede no Rio de Janeiro, berço da SBEM. Era necessário, então, robustecer a organização administrativa e promover a adequação dos estatutos à nova legislação, o que foi feito. Paralelamente, elaborou-se um Planejamento Estratégico, de modo a estabelecer rumos a serem seguidos nos anos seguintes, garantindo a uniformidade de propósitos e a perseguição de metas, por meio de estratégias previamente definidas. A terceira sociedade de endocrinologia do mundo em número de sócios, atrás apenas dos Estados Unidos e Japão, não poderia se manter sem uma administração profissional.

O processo de evolução não parou aí. As sociedades irmãs, Associação Brasileira para o Estudo da Obesidade e Síndrome Metabólica (ABESO), a Sociedade Brasileira de Diabetes (SBD) e a Sociedade Brasileira do Metabolismo Ósseo e Mineral (SOBEMON) estreitaram seus laços de parceria com a SBEM, responsabilizando-se pelos respectivos departamentos de Diabetes, Obesidade e Metabolismo Ósseo e Mineral.

Outro passo importante foi a realização de campanhas públicas sobre temas de Endocrinologia, como autoexame da tiróide, escola saudável, diagnóstico e tratamento do diabetes. O fortalecimento da comunicação social, também contribuiu para tornar a especialidade mais visível e conhecida, o que se fez pela página na Internet e pela atividade da assessoria de jornalismo, além das inúmeras inserções na mídia obtidas pelas assessorias de imprensa.

A atualização profissional e a produção científica também não foram esquecidas. As assinaturas de periódicos internacionais à disposição dos sócios, através da Internet, democratizaram o acesso às pesquisas e revisões mais recentes. Os Arquivos Brasileiros de 
Endocrinologia e Metabologia, desde 2004 indexados no MedLine, ganharam número maior de edições e de páginas por edição. Criaram-se cursos on-line, webmeetings e um blog para discussão de temas endócrinos, frutos do trabalho colaborativo dos departamentos científicos e das comissões de Educação Médica Continuada, de Valorização de Novas Lideranças e de Comunicação Social.

As relações internacionais se fortaleceram e vários jovens pesquisadores brasileiros foram encaminhados para estágios nos Estados Unidos, tendo o Brasil inaugurado o International Scholar Program da Endocrine Society. A projeção internacional se completou com a realização do ICE2008 (13 $3^{\text {th }}$ International Congress of Endocrinology), que contou com cerca de seis mil participantes, metade do Brasil, e que foi unanimemente elogiado pelos representantes das sociedades internacionais de Endocrinologia.

Diante de todas estas conquistas, suceder as diretorias lideradas por Amélio de Godoy Matos, Valéria Guimarães, Marisa Coral e Ruy Lyra, para citar apenas os presidentes deste milênio, não será tarefa simples, mas não nos assusta. A equipe de diretores, montada com endocrinologistas de diversas regiões do país, saberá representar e defender os interesses dos associados e será competente para exercer suas funções específicas. Além disso, as regionais, as comissões e os departamentos estão cada vez mais ativos e produtivos. Este trabalho de todos é que faz a Sociedade crescer e evoluir.

Esta é a primeira Diretoria Nacional que não é representada por uma Regional e a primeira eleita pelo voto direto dos associados. O desafio da experiência nova é estimulante. Cônscios da responsabilidade que isto representa, fizemos a primeira reunião de Diretoria durante o ICE2008, no dia seguinte à divulgação do resultado da eleição. Foram discutidas algumas providências administrativas básicas e estabeleceu-se o compromisso de manter todas as conquistas das diretorias anteriores. Além disso, entendemos que é necessária uma atuação mais direta da Sociedade junto aos órgãos governamentais. Ações de saúde são necessárias para prevenir e combater as duas grandes epidemias endócrinometabólicas da atualidade: obesidade e diabetes melito.

Foi identificada, ainda, a necessidade de oferecer assessoria dos nossos departamentos para outras ações, dentro da nossa especialidade, de modo a que venham a atender às necessidades dos nossos pacientes.

O número de endocrinologistas na rede pública de saúde é insuficiente: é preciso aumentá-lo, através de concursos públicos. Inúmeros casos de cegueira por retinopatia, diálise por insuficiência renal, amputações por vasculopatia, fraturas osteoporóticas, doenças cardiovasculares e internações poderiam ser evitados se houvessem mais ambulatórios de endocrinologia. Além disso, os custos do tratamento das doenças tiroidianas, por exemplo, são menores quando os pacientes são encaminhados a um endocrinologista $(2,3)$, o que significa melhor utilização das verbas públicas para a saúde.

Temos dois anos de trabalho intenso pela frente. Pretendemos intensificar a participação de todos os associados, através dos meios de comunicação de que dispomos, para que a SBEM represente fielmente os endocrinologistas. Sempre que necessário serão realizadas pesquisas de opinião, para orientar as ações da Diretoria Nacional. O apoio e a cooperação da Comissão de Acompanhamento do Planejamento Estratégico, agora formada pelos últimos quatro presidentes e o atual, será imprescindível. A experiência passada ajuda a construir o presente e a planejar o futuro.

\section{REFERÊNCIAS}

1. Karlberg JP. Trends in disease focus of drug development. Nat Rev Drug Discov. 2008;7:639-40.

2. Wu SY, Weiss RE. Radioiodine imaging in the primary care of thyroid disease. Postgrad Med. 2006;119:70-7.

3. Ortiz R, Hupart KH, DeFesi CR, Surks MI. Effect of early referral to an endocrinologist on efficiency and cost of evaluation and development of treatment plan in patients with thyroid nodules. J Clin Endocrinol Metab. 1998;83:3803-7. 